\title{
Teres Minor Innervation and Injection Site
}

\author{
Inervación y Sitio de Inyección del Músculo Redondo Menor \\ Je-Hun Lee*; Anna Jeon**; ChangMin Seo**; Sooil Kim ${ }^{* * * *} \&$ Young-Gil Jeong*
}

LEE, J. H.;JEON, A.; SEO, C. M.; KIM, S. \& JEONG, Y. G. Teres minor innervation and injection site. Int. J. Morphol., 34(2):593$596,2016$.

SUMMARY: The aim of this study was to elucidate the injection point on the teres minor (TM) for effective injection. Thirty-two specimens from 16 adult Korean cadavers (10 males and 6 females, age ranging from 42 to 102 years) were used in the study. The reference line between the inferior point on the inferior angle of the scapula (IA) and the most prominent point on the acromial angle of the scapula (AA) on the surface were identified. The measurements expressed the two above-mentioned parameters as $\mathrm{X}$ and $\mathrm{Y}$ coordinates in relation to the reference line. The $\mathrm{X}$ coordinate was located at $128.1 \pm 10.4 \mathrm{~mm}(78.1 \pm 5.7 \%)$ and the $\mathrm{Y}$ coordinate was located at $25.3 \pm 7.6 \mathrm{~mm}(15.5 \pm 4.8 \%)$. The recommended site according to this can be used for injections in patients with TM stiffness.

\section{KEY WORDS: Teres minor; Nerve branch; Botulinum toxin; injection}

\section{INTRODUCTION}

Teres minor (TM) muscle arises from the dorsal surface of the axillary border of the scapula for the upper two-thirds of its extent, and from two aponeurotic laminae, one of which separates it from the infraspinatus muscle, the other from the teres major muscle.

The function of TM muscle is mainly lateral rotation, and the second function is shoulder adduction, along with the infraspinatus muscle. However, these two muscles are very clearly distinguished by their nerve innervations. The TM muscle is supplied by the axillary nerve whereas the infraspinatus is supplied by the suprascapular nerve. If muscle stiffness occurs in any one of the muscles, it causes limitation of shoulder joint movement (Hung et al., 2010).

One of the treatments for muscle stiffness is chemical neurolysis with phenol, alcohol and botulinum toxin (BTX) injections (Deltombe et al., 2004). BTX blocks the release of acetylcholine from nerve endings at the neuromuscular junction, and selectively affects motor nerves without affecting sensory nerves (Bhakta et al., 1996). Furthermore, low level of side effects of BTX, compared to phenol and alcohol, has made it a popular choice in the management of spasticity. The sustained benefits and safety of BTX injections in the management of spasticity and their efficacy in improving the quality of movement of the extremities have been supported by many clinical studies (Hurvitz et al., 2003; Kawamura et al., 2007; Lowe et al., 2007). To achieve maximal effects, it is recommended that these injections be placed close to regions where neuromuscular junctions are most densely distributed.

Based on this consideration, a large number of studies using cadaver dissections have been performed to target various parts of the body. A few articles reported the MEP for the flexor digitorum profundus (Hwang et al., 2007), triceps surae muscles (Kim et al., 2005; Sook Kim et al., 2002) and posterior compartment of the leg (Apaydin et al., 2008). However, investigation of the TP muscle has received less attention.

The aim of this study was to elucidate the injection point on the TM muscle for effective injection.

\section{MATERIAL AND METHOD}

Thirty-two specimens from 16 adult Korean cadavers (10 males and 6 females, age ranging from 42 to 102 years) were used in the study. Cases with pathological changes or shoulder trauma were excluded.

* Department of Anatomy, College of Medicine, Konyang University of Korea, Daejeon, Korea.

** Department of Anatomy, College of Medicine, Chungang University of Korea, Seoul, Korea.

*** Department of Anatomy, College of Medicine, Chungnam National University of Korea, Daejeon, Korea.

This research was supported by basic science research program through the national research foundation of Korea (NRF) funded by the Ministry of Education, Science and Technology (NO. 2014R1A1A1006195). 
The dissections were performed in the prone position and the upper limb was extended and abducted at $45^{\circ}$. The incision was made from the middle part of the trunk to the shoulder line on the posterior surface. After removing the skin around the shoulder region, the TM muscle and triangular space were identified. After that, the nerve that innervates TM muscle was carefully identified. We investigated the number of nerve branches and the nerve point of insertion of the TM muscle belly according to the reference line.

The reference line between the inferior point on the inferior angle of the scapula (IA) and the most prominent point on the acromial angle of the scapula (AA) on the surface were identified. The measurements expressed the two above-mentioned parameters as $\mathrm{X}$ and $\mathrm{Y}$ coordinates in relation to the reference line. The $\mathrm{X}$ coordinate was expressed in both a percent with the absolute distances along the reference line and the $\mathrm{Y}$ coordinate was expressed in both a percent with the absolute distances perpendicular to the reference line.

All statistical analyses were carried out using SPSS version 17.0 (SPSS Inc., Chicago, IL., USA). Comparisons between variables in male and female cadavers were performed using the t-test. P values less than 0.05 were considered statistically significant.

\section{RESULTS}

All TM muscles were innervated by the axillary nerve. The mean length of the reference line was $169.4 \pm 7.6 \mathrm{~mm}$. One nerve branch was observed to branch out from the axillary nerve and then some specimens divided into two or three branches. The number of nerve branches that entered the TM muscle belly was investigated. Twenty-two (69\%) cases had one branch, $9(28 \%)$ cases had two branches, and 1 (3\%) case had three branches.

In male cadavers, the $\mathrm{x}$ coordinate was located at $131.2 \pm 9.3 \mathrm{~mm}(77.5 \pm 5.2 \%)$ and the y coordinate was located at $26.8 \pm 7.9 \mathrm{~mm}$ $(15.9 \pm 5.0 \%)$. In female cadavers, the $\mathrm{x}$ coordinate was located at $118.3 \pm 7.5 \mathrm{~mm}$ $(80.1 \pm 7.1 \%)$ and the y coordinate was located
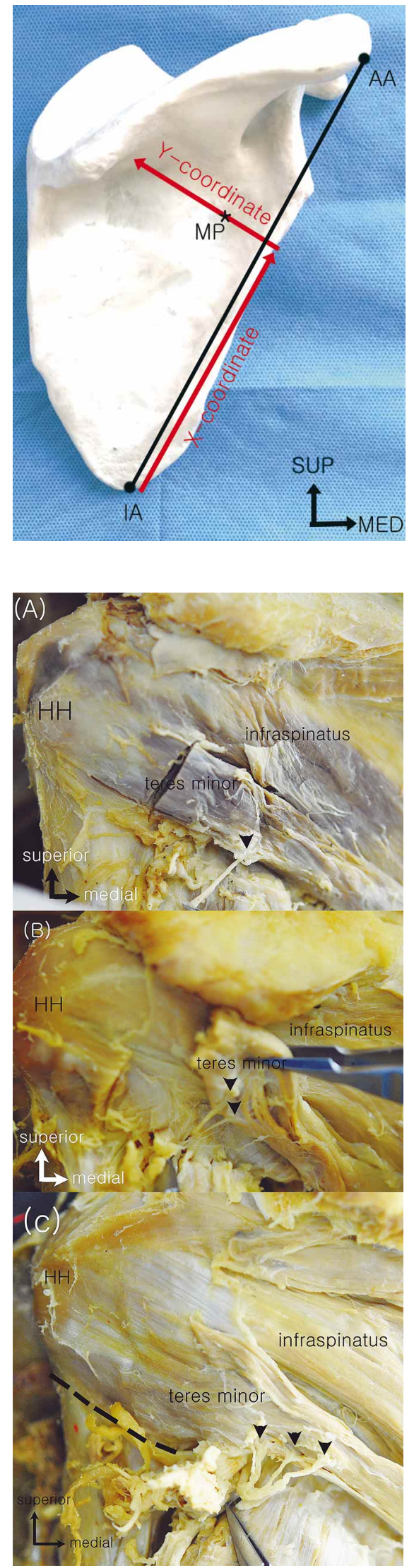

Fig. 1. Drawing showing the reference line and the measurement methods. We expressed the parameters concerning the transverse $(\mathrm{X})$ and vertical $(\mathrm{Y})$ coordinates in relation to a reference line. The transverse $(\mathrm{X})$ coordinates were expressed as percentage and absolute distances of the reference line with the inferior point of inferior angle of as starting point, and the vertical (Y) coordinates were expressed as the percentage and absolute distance perpendicular to the reference line (X-coordinate). $\mathrm{IA}=$ inferior point of inferior angle of scapula, $\mathrm{AA}=$ prominent point of acromial angle of scapula, $\mathrm{SUP}=$ superior, $\mathrm{MED}=$ medial .

Fig. 2. Photographs of the dissected teres minor muscle showing a nerve branch to teres minor on posterior view. $(\mathrm{A})=$ one nerve branch, $(\mathrm{B})=$ two nerve branches, $(\mathrm{C})=$ three nerve branches. $\mathrm{HH}=$ humeral head. The arrow-heads indicate the nerve point to enter the muscle belly. 
Table I. The results (with $\pm \mathrm{SD}$ ) of the variables (mm).

\begin{tabular}{lccc}
\hline V ariables & Male (\%) & Female (\%) & Combined (\%) \\
\hline Reference length & $169.4 \pm 7.6$ & $148.4 \pm 11.1$ & $164.3 \pm 12.4$ \\
X coordinate length & $131.2 \pm 9.3(77.5 \pm 5.2)$ & $118.3 \pm 7.5(80.1 \pm 7.1)$ & $128.1 \pm 10.4(78.1 \pm 5.7)$ \\
Y coordinate length & $26.8 \pm 7.9(15.9 \pm 5.0)$ & $20.7 \pm 4.1(14.1 \pm 3.8)$ & $25.3 \pm 7.6(15.5 \pm 4.8)$ \\
\hline
\end{tabular}

$*(\%)$ means the index value for the reference length.

at $20.7 \pm 4.1 \mathrm{~mm}(14.1 \pm 3.8 \%)$. In a combination of both male and female cadavers, the $\mathrm{x}$ coordinate was located at $128.1 \pm 10.4 \mathrm{~mm}(78.1 \pm 5.7 \%)$ and the y coordinate was located at $25.3 \pm 7.6 \mathrm{~mm}$ $(15.5 \pm 4.8 \%)$. There was no significant difference between male and female cadavers $(\mathrm{P} \geq 0.05)$. However, this study showed the results of variables in male and female cadavers separately.

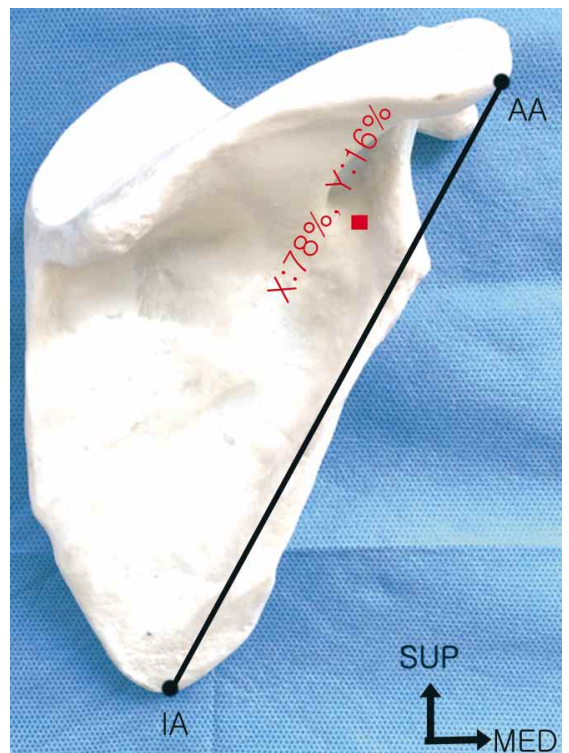

Fig. 3. Schematic mapping of recommended injection site for the teres minor muscle.

\section{DISCUSSION}

Some studies (Chafik et al., 2013) showed that a stout fascial sling may be the potential site of greatest compression of the primary nerve to TM muscle, and our study identified the tight fascia but did not find the nerve that enters the fascia. The study did not conclude the exact reason; however, that might be due to the difference in population.
The posterior shoulder muscles include posterior deltoid, infraspinatus, and TM muscles. The muscle stiffness restricted internal rotation (Lin \& Yang, 2006). The injection based on our results would be helpful to free the shoulder movement.

Many studies have demonstrated the effectiveness of BTX as a neuromuscular block for the treatment of spasticity in patients with diplegia and hemiplegia (Manganotti et al., 2007; Colovic et al., 2014; Fehlings et al., 2000). BTX acts at the neuromuscular junction. Histological studies in rabbit models have shown that injections only $5 \mathrm{~mm}$ away from the end-plate result in a $50 \%$ decrease in toxin denervation and paralysis (Shaari \& Sanders, 1993). Therefore, to achieve maximal effects, it is recommended that these injections be placed close to the regions where neuromuscular junctions are most densely distributed (Lee et al., 2010).

In the present study, IA was chosen and the AA on the dorsal aspect was used as the reference point; it is more prominent and easy to palpate from the surface than the other points on the scapula. Easy identification is especially important in patients with fixed upper extremities, which could make accurate identification of anatomic landmarks technically difficult.

The anatomical study about the axillary nerve or TM muscle was reported by a few authors. Kang et al. (2014) studied the nerve composition and found that more than half of the cases originated from $\mathrm{C} 5$ and $\mathrm{C} 6$. Another study investigated the surrounding structure on quadrangular space, TM and deltoid muscles using metric methods. However, our study focused on the nerve that entered into TM muscle, and when the surgeon is confronted with injection into TM muscle, these results will be helpful.

There is very limited data on the nerve branch to TP. The results of the present study showed that the dense area of the nerve branch to TM muscle was located in $78 \%$ of cases on the X-coordinate and in $16 \%$ of cases on the Y-coordinate from the reference point. When considering the reference line and standard deviation of these results, the interval of values on the X and Y-coordinate was located not more than $2.0 \mathrm{~cm}$. BTX is known to diffuse 1.5 or $2.0 \mathrm{~cm}$ from injection sites at low doses and over the entire muscle across muscle fascia at higher doses (Lee et al.; Sätilä et al., 2005).

In practice, the clinician injects the BTX just on the posterior surface of the scapula on the medial aspect. The following is recommended: for the nerve branch that entered TM, the dense area was located in $78 \%$ of cases on the X coordinate and in $16 \%$ of cases on the $\mathrm{Y}$ coordinate region. These areas can be used for injections in patients with TM muscle stiffness.

ACKNOWLEDGEMENTS. We thank for donated bodies to our medical school. 
LEE, J. H.;JEON, A.; SEO, C. M.; KIM, S. \& JEONG, Y. G. Inervación y sitio de inyección del músculo redondo menor. Int. J. Morphol., 34(2):593-596, 2016.

RESUMEN: El objetivo fue determinar el punto de inyección en el músculo redondo menor (MRM) para llevar a cabo una correcta inyección. Se utilizaron 32 muestras correspondientes a 16 cadáveres adultos coreanos (10 hombres y 6 mujeres, entre 42 a 102 años de edad). Se identificó en la superficie la línea de referencia entre el punto inferior en el ángulo inferior de la escápula (AI) y el punto más prominente en el ángulo acromial de la escápula (AA). Las mediciones expresaron los dos parámetros mencionados anteriormente como coordenadas $\mathrm{X}$ e Y en relación con la línea de referencia. La coordenada $X$ se encuentra a $128,1 \pm 10,4 \mathrm{~mm}(78,1 \pm 5,7 \%)$ y la coordenada $Y$ estaba situada a $25,3 \pm 7,6 \mathrm{~mm}(15,5 \pm 4,8 \%)$. El sitio recomendado de acuerdo a estos resultados se puede usar para preparaciones inyectables en pacientes con rigidez del MRM.

PALABRAS CLAVE: Músculo redondo menor; Ramo del nervio; Toxina botulínica; Inyección.

\section{REFERENCES}

Apaydin, N.; Loukas, M.; Kendir, S.; Tubbs, R. S.; Jordan, R.; Tekdemir, I. \& Elhan, A. The precise localization of distal motor branches of the tibial nerve in the deep posterior compartment of the leg. Surg. Radiol. Anat., 30(4):291-5, 2008.

Bhakta, B. B.; Cozens, J. A.; Bamford, J. M. \& Chamberlain, M. A. Use of botulinum toxin in stroke patients with severe upper limb spasticity. $J$. Neurol. Neurosurg. Psychiatry, 61(1):30-5, 1996.

Chafik, D.; Galatz, L. M.; Keener, J. D.; Kim, H. M. \& Yamaguchi, K. Teres minor muscle and related anatomy. J. Shoulder Elbow Surg., 22(1):108-14, 2013.

Colovic, H.; Dimitrijevic, L.; Stankovic, I.; Nikolic, D.; Radovic-Janosevic, D. \& Zivanovic, D. The effects of botulinum toxin type A on improvement and dynamic spastic equinus correction in children with cerebral palsy - preliminary results. Arch. Med. Sci., 10(5):979-84, 2014.

Deltombe, T.; De Wispelaere, J. F.; Gustin, T.; Jamart, J. \& Hanson, P. Selective blocks of the motor nerve branches to the soleus and tibialis posterior muscles in the management of the spastic equinovarus foot. Arch. Phys. Med. Rehabil., 85(1):54-8, 2004.

Fehlings, D.; Rang, M.; Glazier, J. \& Steele, C. An evaluation of botulinumA toxin injections to improve upper extremity function in children with hemiplegic cerebral palsy. J. Pediatr., 137(3):331-7, 2000.

Hung, C. J.; Hsieh, C. L.; Yang, P. L. \& Lin, J. J. Relationships between posterior shoulder muscle stiffness and rotation in patients with stiff shoulder. J. Rehabil. Med., 42(3):216-20, 2010.

Hurvitz, E. A.; Conti, G. E. \& Brown, S. H. Changes in movement characteristics of the spastic upper extremity after botulinum toxin injection. Arch. Phys. Med. Rehabil., 84(3):444-54, 2003.

Hwang, K.; Jin, S.; Hwang, S. H.; Lee, K. M. \& Han, S. H. Location of nerve entry points of flexor digitorum profundus. Surg. Radiol. Anat., 29(8):617-21, 2007.

Kang, M. S.; Woo, J. S.; Hur, M. S. \& Lee, K. S. Spinal nerve composition and innervation of the axillary nerve. Muscle Nerve, 50(5):856-8, 2014.

Kawamura, A.; Campbell, K.; Lam-Damji, S. \& Fehlings, D. A randomized controlled trial comparing botulinum toxin A dosage in the upper extremity of children with spasticity. Dev. Med. Child. Neurol., 49(5):331-7, 2007.
Kim, M. W.; Kim, J. H.; Yang, Y. J. \& Ko, Y. J. Anatomic localization of motor points in gastrocnemius and soleus muscles. Am. J. Phys. Med. Rehabil., 84(9):680-3, 2005.

Lee, J. H.; Kim, H. W.; Im, S.; An, X.; Lee, M. S.; Lee, U. Y. \& Han, S. H. Localization of motor entry points and terminal intramuscular nerve endings of the musculocutaneous nerve to biceps and brachialis muscles. Surg. Radiol. Anat., 32(3):213-20, 2010.

Lin, J. J. \& Yang, J. L. Reliability and validity of shoulder tightness measurement in patients with stiff shoulders. Man. Ther., 11(2):14652,2006

Lowe, K.; Novak, I. \& Cusick, A. Repeat injection of botulinum toxin A is safe and effective for upper limb movement and function in children with cerebral palsy. Dev. Med. Child. Neurol., 49(11):823-9, 2007.

Manganotti, P.; Zaina, F.; Falso, M.; Milanese, F. \& Fiaschi, A. Evaluation of botulinum toxin therapy of spastic equinus in paediatric patients with cerebral palsy. J. Rehabil. Med., 39(2):115-20, 2007.

Sätilä, H.; Iisalo, T.; Pietikäinen, T.; Seppänen, R. L.; Salo, M.; Koivikko, M.; Autti-Rämö, I. \& Haataja, R. Botulinum toxin treatment of spastic equinus in cerebral palsy: a randomized trial comparing two injection sites. Am. J. Phys. Med. Rehabil., 84(5):355-65; quiz 366-7, 392, 2005.

Shaari, C. M. \& Sanders, I. Quantifying how location and dose of botulinum toxin injections affect muscle paralysis. Muscle Nerve, 16(9):964-9, 1993.

Sook Kim, H.; Hye Hwang, J.; Lee, P. K.; Kwon, J. Y.; Yeon Oh-Park, M.; Moon Kim, J. \& Ho Chun, M. Localization of the motor nerve branches and motor points of the triceps surae muscles in korean cadavers. Am. J. Phys. Med. Rehabil., 81(10):765-9, 2002.

Correspondence to:

Young-Gil Jeong

Department of Anatomy

College of Medicine

Konyang University of Korea

Daejeon

KOREA

Email: ygjeong@konyang.ac.kr 